\title{
Artificial Intelligence in Higher Education: Challenges and Opportunities
}

\author{
Susan Nwadinachi Akinwalere ${ }^{1}$ and Ventsislav Ivanov ${ }^{2}$
}

\begin{abstract}
According to various international reports, Artificial Intelligence in Education (AIEd) is one of the emerging fields in education technology. Whilst it has been around for about thirty years, educators remain unclear as to how to take full pedagogical advantage of $A I$ on a broader scale and how it could have a meaningful impact on teaching and learning in higher education. This paper aims to evaluate Artificial Intelligence within Higher Education, focussing on the opportunities and challenges it presents. It also investigates the educational implications of emerging technologies on the way students learn and how institutions teach and evolve. The paper gathers some examples of the introduction of AI in education in a bid to establish equitable, quality education for all. Firstly, the paper analyses how AI can be used to improve learning outcomes, presenting examples of how AI technology can help education systems use data to improve equity and quality in Higher Education. The paper also addresses the benefits and challenges of introducing AI in educational settings and the potential risks of such an endeavour. Finally, we put forward some recommendations for AI in education, with a focus on establishing discussions around the uses, possibilities and risks of AI in education for sustainable development.
\end{abstract}

Keywords: Artificial Intelligence; Higher Education

\section{Introduction}

With the rise of technological advancements and the increasing use of artificial intelligence, there seem to be offers of immense opportunities which significantly require a change in the direction of the new realities we find ourselves in this digital age. Therefore, it is unsurprising that artificial intelligence will inevitably change the way higher education works.

Artificial intelligence is the technological future that happens to make the lives of human beings a lot easier. It is a booming technological domain capable of altering every aspect of our social interactions (Bostrum, 2017). In education, AI has been seen to have already begun initiating new teaching and learning solutions that are currently under trial and undergoing restructuring in different contexts (Bostrum, 2017). AI requires advanced infrastructures and an ecosystem of thriving innovators. We are, therefore, on the threshold of a new era in the way of learning. In this age of big data and digitalisation, we happen to all discover that individual information footprints are left behind, which results in a myriad of data, which eventually allows human and societal behaviour to be objectively quantified and measured

\footnotetext{
${ }^{1}$ Dr Susan Nwadinachi Akinwalere, Oxford Business College, UK. E-mail: susanakinwalere@yahoo.com.

${ }^{2}$ Dr Ventsislav Ivanov, Oxford Business College, UK. E-mail: ventsislav.ivanov@oxfordbusinesscollege.ac.uk
} 


\section{Artificial Intelligence in Higher Education}

and, therefore, easily tracked, modelled and, to a certain extent, predicted. This phenomenon surrounding information footprints is referred to as 'datafication' (Mayer-Schönberger and Cukier, 2014) and also affects the education sector.

Artificial intelligence will only add value to the quality of training. There have been lots of arguments around the development of artificial intelligence as having more potential to change higher education than any other technological advancement. For instance, Bates (2018) have listed the following goals for AI in higher education:

- increase outcomes

- increase access

- increase retention

- lower cost

- decrease time to completion

However, these are goals that are on the verge of actualisation. What has been the case since the 2020s? To date, very little has been discussed about the possibilities and limitations of AI in education, particularly regarding the extreme problems of least developed countries. With a view to helping bridge this gap, this paper will also discuss various AI technologies that education systems have begun to use and explore how they have helped, or could help, improve learning outcomes.

The paper will outline the benefits of introducing artificial intelligence in higher education. However, it is also critical to understand the impact of this on teaching and learning.

\section{Literature Review}

\section{AI in education (AIEd)}

Artificial intelligence is already in widespread use in some areas of society. However, in terms of its direct impact on teaching and learning, much has been promised but, as yet, little has been accomplished. Zuboff (2019) provides a good overview of the different areas in which AI is being applied in higher education and an indication of which areas researchers have tended to focus on. He identifies four key applications of AI in teaching and learning:

- profiling and prediction

- intelligent tutoring systems

- assessment and evaluation

- adaptive systems and personalisation.

In recent years, there has been a resurgence in the development of machine intelligence, deep learning and cognitive architectures, and many commentators predict a bright future for AI across all sectors of society (Kaku, 2012; Kelly, 2017). For example, Tegmark (2018) argues that we have yet to attain the level of 'Artificial General Intelligence', where the processing capabilities of machines match the cognitive capabilities of human beings, while Bostrom (2017) suggests that we have endured an 'AI Winter' in which proponents of AI have suffered loss of credibility. Students now find themselves at the forefront of a vast array of possibilities and challenges for learning and teaching in higher education. In addition, solutions for humanAI interaction and collaboration are already available to help people with disabilities (Kübler 
et al., 2015). They can inspire educators to apply them to educational contexts to create a more engaging process for both learners and teachers. This is described as "a crossbreed of a human and a machine" (Ford, 2018, p. 15). Steps to combine human capacities with new technologies are already being taken and developed at an accelerated pace. Complex computer systems using machine learning algorithms can serve people of different abilities and engage, to a certain degree, in human-like processes and complex processing tasks that can also be applied to teaching and learning (Andrews et al., 2016). This creates a wealth of opportunities for higher education institutions.

In the 1950s, Alan Turing proposed an answer to when a system designed by a human can be deemed 'intelligent.' Turing suggested the imitation game, which tests the capacity of a human listener to distinguish between a conversation with a machine or another human. If such a distinction is not detected, we say that it is an intelligent system, or "artificial intelligence (AI)" (Russell and Norvig, 2010, p. 21).

In fact, the focus on AI solutions dates back to the 1950s. In 1956, John McCarthy provided one of the first definitions of AI, which still informs researchers today: "The study [of artificial intelligence] is to proceed on the basis of the conjecture that every aspect of learning or any other feature of intelligence can in principle be so precisely described that a machine can be made to simulate it" (Russell and Norvig 2010, pg 15).

Artificial intelligence is currently progressing at an accelerated pace, and it is already having an impact on the nature of service provision within higher education. For example, universities already use an incipient form of artificial intelligence, IBM's supercomputer 'Watson'. This solution currently provides advice for students at Deakin University in Australia at any time of day, 365 days a year (Deakin University, 2014). According to experts, the use of AI in education is expected to grow by 43\% in the period 2018-2022, although the Horizon Report 2019 Higher Education Edition (Becke et al., 2018) predicted that AI applications related to teaching and learning are projected to grow even more significantly than that. 'Contact North', a major Canadian non-profit online learning society, concludes that "there is little doubt that [AI] technology is inexorably linked to the future of higher education" (Contact North, 2018, p. 5).

A vast array of research shows that learning is a social exercise; interaction and collaboration are at the heart of the learning process (see, for example, Jonassen et al., 1995). However, as Salmon (2000) argues, online collaboration has to be facilitated and moderated. AIEd can contribute to collaborative learning by supporting adaptive group formation based on learner models, by facilitating online group interaction or by summarising discussions that can then be used by a human tutor to guide students towards the aims and objectives of a particular course.

These developments are sometimes described as 'modern' AI to differentiate them from earlier applications of computer-based learning, perhaps inaccurately described as AI previously. However, there is currently little evidence of a major breakthrough in the application of 'modern' AI to teaching and learning in higher education, with the exception perhaps of learning analytics. 


\section{Implications and Contribution to Knowledge}

Although concerted efforts have been made over the last two decades to promote, develop and update the digital skills of instructors, researchers and administrators, the challenges now seem to be much more complex. In the last few years, one of the most interesting developments observed in the evolution of AI has been the diversification of new interfaces (Bayne, 2015). They extend far beyond the keyboard and mouse, allowing users (especially non-expert users) to interact with AI simply by using voice or image recognition. This makes the interaction with advanced systems more transparent and creates possibilities for users with lower levels of skills to benefit. Therefore, practical and realistic ideas and recommendations about further research and work in the emerging field of artificial intelligence and higher education will be made at the end of this paper, in addition to highlighting its benefits and challenges.

\section{Examples of Artificial Intelligence cases in Higher Education}

The role of technology is not only in equipping students with information and communications technology (ICT) skills but also in achieving quality education, free from the constraints of location and time, and to encourage curiosity, creativity and collaboration. Quality education is not only a fundamental human right but is also directly linked to the financial prosperity of citizens and nations. Artificial intelligence (AI) promises important benefits for education, such as personalised learning according to the preferences of each student, helping them learn at their own pace and control iterations to improve their mastery of the topic. Therefore, university leaders believe that one benefit of AI in the future will be its ability to "assess students, provide feedback and generate and test scientific hypotheses at least as well as humans can" (Alexander et al., 2019). In the following section, we examine a few examples of the use of AI in higher education.

\section{MIP Politecnico di Milano Graduate School of Business}

MIP Politecnico di Milano Graduate School of Business is working with Microsoft to develop FLEXA, a new digital platform powered by Microsoft Azure and AI, which enables students to assess their professional skills and provides them with personalised content to help fill skills gaps between their career goals and existing studies.

FLEXA is helping to develop personalised learning pathways that take into account assessment and the amount of time at a student's disposal. FLEXA is also intended to address the needs for lifelong learning (Alexander et al., 2019).

\section{University of New South Wales (UNSW) in Sydney}

Professor Kellerman of the University of New South Wales (UNSW) in Sydney embarked on a journey to implement an engaging learning collaboration environment for an engineering class using Microsoft Teams as its backbone and Microsoft Stream for video recording. Professor Kellermann then implemented a Question Bot (QBot) that assigned students' questions to the relevant teaching assistant (TA) (UNSW School of Computer Science and Engineering, 2021).

The Q+A pairs were used to build a Knowledge Base to enable the bot to answer students' questions and also look up previous answers, which may be buried in old threads. The student 
can still request a TA to answer the question. The bot can also search video lecture transcripts and deliver time-stamped video clips to students. The use of these technologies has helped Professor Kellermann to create an AI-powered learning community and its use has been received enthusiastically by the students, with class satisfaction jumping to $99 \%$ (UNSW School of Computer Science and Engineering, 2021).

\section{Pearson Group}

AI is also used to enhance foreign language teaching. In January 2018, Microsoft Asia Research signed a strategic cooperation agreement with Pearson Group to further solidify the cooperation between AI and English education. Previously, the two sides jointly launched "LongWen Xiaoying", an artificial intelligence-driven interactive English learning application. Acquiring foreign language skills is crucial as it applies to all ages and education levels, from Key stage 12 to Higher Education and Lifelong Learning (Pearson, 2021).

Reducing assessment activities is a huge time saver for teaching staff - and we see such engagement with Microsoft's partner GamaLearn which happens to be an AI technology skilled in authoring, proctoring and marking in order to provide automation, self-based, and personalised assessment. This AI-Cyber software assists organisations in ensuring the integrity of exam sessions on a large scale and how it works is to capture different compromising events, which set out to highlight problems during session and ensure that forensic dashboards, etc are provided (Pearson, 2021).

\section{Washington State University}

Washington State University informed the public of a partnership with edtech startup 'Cialfo' to extend its recruiting reach and directly engage with more than a quarter of a million international high school students using Cialfo's AI-driven Explore platform. Cialfo creates a network that brings universities, high school counsellors, parents and students together throughout their recruitment journey and is used by students across 100 countries. It is hoped the partnership will help WSU reach more students and achieve its year-round goals, despite the current challenges.

\section{Georgia State University}

Georgia State University has adopted AI to decrease the number of students who accept offers of admissions but subsequently do not show up for fall enrolment. This common phenomenon is often referred to as 'summer melt'. On a mission to decrease summer melt, GSU discovered that many of the obstacles to student matriculation were as simple as immunisation records or help with class registration (Alexander et al., 2019). However, with 2,000 calls a day during the start of a new semester, GSU could not possibly reach every student and help them with the registration process. To address this issue, Georgia State University developed "Pounce", an AI chatbot to answer students' frequently asked questions. The chatbox answers questions at any time of the day or night, allowing students to ask as many questions as they need at their leisure. This takes place over text messages, thus providing students with a comfortable and familiar interface. During its launch, Pounce answered over 200,000 questions and decreased summer melt by 20\% (Alexander et al., 2019). 


\section{Rensselaer Polytechnic Institute - China}

Rensselaer Polytechnic Institute's immersion lab features a 360-degree projection onto 15foot walls, transporting students to the streets of Beijing, China. The system allows participants to "practice conversational skills, improve their vocabulary, pronunciation and cultural knowledge" with AI characters. Students participating in the immersion lab master the language twice as quickly as students in traditional classrooms (Janalta Interactive, 2021). Furthermore, systems are already being used to monitor student participation and expressions using face recognition technology in classrooms (so-called Intelligent Classroom Behaviour Management System, Smart Campus), which are displayed to the teacher on a dashboard. This is an example of educational surveillance (Janalta Interactive, 2021).

\section{Challenges and opportunities of AI}

The complexity of human intelligence had been long underestimated, especially in the expert systems field. Technological limitations and managerial challenges still remain in the development of expert systems. However, with the aid of state-of-the-art technologies, the future of expert systems seems bright despite some setbacks.

\section{Opportunities of AI}

\section{Smart Campus}

The University experience can be overwhelming, particularly for new and international students who have to navigate a whole set of questions and sources of information. Chatbots utilising the Microsoft bot framework help students get their questions answered quickly. Griffith University's 'Sam' helps students find the information they are looking for. The University of Sydney's 'FinBot' helps its finance department respond rapidly to questions regarding POs and other related issues. The University of Canberra developed a student chatbot called Lucy to respond to student inquiries. It is important to note that the user can always flag the question to be addressed by a human if the answer provided is unsatisfactory (Sharma, 2021).

\section{Research}

A key challenge for every researcher is the explosion of knowledge creation, with the number of academic papers doubling within a decade. In addition, traditional citation metrics are not adequate, as they are quantitative only. Moreover, citations do not carry equal significance, and it has been proven that citation counts can be rigged. In addition, bibliographic searches rely on lengthy queries to capture key word variations, and this process has to be repeated across multiple databases. Microsoft Academic (MA) is a Microsoft Research project exploring how to assist academics in conducting scientific research by leveraging the computer's' cognitive power. MA uses natural language processing (NLP) techniques to give each paper discovered by Bing crawler a semantic label. By analysing 230 million papers, MA has built a graph of $710 \mathrm{~K}+$ semantic labels derived using self-supervised learning. Each paper is ranked by estimating the importance of each entity, such as the authors citing it, using big data and graph analysis. MA also recommends similar papers that do not have a citation relationship (Perera and Aboal, 2020). 
How does MA help researchers to be more productive? Firstly, by powering more insightful bibliographic analysis. This has been used to inform the OECD AI Policy Observatory and the Stanford HCAI AI Index report, for example. Secondly, it helps researchers to reimagine systematic reviews and research literature reviews by acting as an intelligent AI assistant. In collaboration with several organisations, Microsoft Academic has been used to draw on worldwide scientific efforts and results for the New Machine Readable COVID-19 Dataset (Perera and Aboal, 2020).

\section{Teacher and AI collaboration}

AI can help fill needs gaps in learning and teaching and allow schools and teachers to do more than ever before. AI can drive efficiency, personalisation and streamline administrative tasks to give teachers more time and freedom to provide understanding and adaptability — uniquely human capabilities where machines would struggle. By leveraging the best attributes of both machines and teachers, the vision for AI in education is one where they work together in the best interests of the students. Since the students of today will work in a future in which AI is the reality, it is important that our educational institutions expose students to its possibilities and actively use the available technology (UNICEF, 2020).

\section{Differentiated and individualised learning}

Adjusting learning based on an individual student's particular needs has been a priority for educators for years, but AI will provide a level of differentiation that is currently impossible for teachers who have to manage thirty students in each class. Several companies, such as Content Technologies and Carnegie Learning, are currently developing intelligent instruction design and digital platforms that use AI to provide learning, testing and feedback to students from pre- $\mathrm{K}$ to college level, identifying gaps in their knowledge and directing them to new challenges when appropriate (UNESCO, 2019). As AI becomes even more sophisticated, it might be possible for a machine to read the expression on a student's face that indicates they are struggling to grasp a subject and will modify a lesson in response. The idea of customising the curriculum for every student's individual needs is not viable today, but it will be for AIpowered machines (UNESCO, 2019).

\section{Universal access for all students}

Artificial intelligence tools can help make global classrooms available to all, including those who speak different languages or who might have visual or hearing impairments. Presentation Translator is a free plug-in for PowerPoint that creates subtitles in real time for what the teacher is saying. This also creates new possibilities for students who might not be able to attend school due to illness or who require learning at a different level or on a particular subject that is not available at their own institution. AI can help break down silos between schools and between traditional grade levels (Williamson, 2014).

\section{Automate administrative tasks}

An educator spends a tremendous amount of time marking homework and tests. This is where AI can step in and make quick work of these tasks, while at the same time offering recommendations to address learning gaps. Although machines can already grade multiplechoice tests, they are very close to being able to assess written responses as well. As AI steps in to automate administrative tasks, it gives teachers more time to spend with each student. 


\section{Artificial Intelligence in Higher Education}

There is also much potential for AI to create more efficient enrolment and admissions processes (Williamson, 2014).

\section{Challenges of AI}

\section{Adverse outcomes}

The use of artificial intelligence in higher education also involves perils, of course. One is the peril of adverse outcomes. Despite the best intentions of those who develop and use these systems, there will be negative unintended consequences or that can even backfire. To avoid these adverse outcomes, several different factors should be considered. One of the first to consider is the data these tools draw upon. That data can vary in quality, it may be old and outdated, or it may be drawn from a subset of the population that may not align with the students being targeted. For example, AI learning systems that have been tested on students in a particular kind of college or university in California may not have the same outcomes or reflect the same accuracy for students in another part of the country. Similarly, an AI system based on Generation X students may not have the same efficacy for native digital learners.

\section{Comprehensiveness}

Another data aspect concerns comprehensiveness. In other words, does the data include information about a variety of students? There has been much discussion about this recently in terms of facial recognition. Scholars looking at the use of facial recognition by companies such as Google, IBM, Microsoft and Face++ have shown that, in many cases, these tools have been developed using proprietary data or internal data based on employees (Perera and Aboal, 2020). The tools are much more accurate for light-skinned men than light-skinned women or darker-skinned men. For example, in one study, the facial recognition tools had nearly 100 per cent accuracy for light-skinned men but only 65 per cent accuracy for darkskinned women (Perera and Aboal, 2020).

\section{Accuracy}

Again, we face the issue of accuracy. Models are based on correlation; they are not reflective of causation. The point of AI tools and models is to show less intuitive, more attenuated correlations and patterns. Separating which correlations and patterns are accurate and which are simply noise can be difficult.

\section{Output}

An additional, often overlooked, factor in adverse outcomes is output. Developers' decisions shape how the insights that AI systems offer are instructed and interpreted. Some provide detailed information on various elements of student learning or behaviour that instructors and administrators can act upon. Other observations are not as useful in informing interventions. For example, one predictive analytics tool estimated that 80 per cent of the students in an organic chemistry class would not complete the semester. This was not news to the professors, who still wondered what to do. It is important to understand in advance what you want to do with the information these tools provide (Sharma, 2021). 


\section{Implementation}

To use these systems responsibly, teachers and staff must understand not only their benefits but also their limitations. At the same time, schools need to create very clear protocols for what employees should do when algorithmic evaluations or recommendations do not align with their professional judgment. They must have clear criteria about when it is appropriate to follow or override computer-generated insights to prevent unfair inconsistencies.

\section{AiLM Model - Artificial Intelligence Learning Model in Higher Education}

Before embarking on explanations of our model below, it is pertinent to understand the nature and definition of artificial intelligence as it relates to higher education: "Artificial intelligence is a binary machine with adaptive input, which resembles a rational person in the whole process of connecting with bigher education. The binary origin of the fact that this intellect can be trained (for the benefit of learners) or a trainer (for the benefit of trainers). By a complete process related to higher education, we mean the process of teaching, learning and administrative services" (Janalta Interactive, p. 9 2021).

Fullan and Donnelly (2013) describe three forces essential to the delivery of technology-driven changes in learning (Luckin et al., 2016). These are:

Pedagogy - The basis for AI should start with pedagogy as the first major change in the way of teaching - an awareness of the fact that the teaching process should not be lured by modern technologies but should focus on learning. In other words, modern technology must support the teaching process, not replace it.

Systems Change - The system has already changed and the era of blended learning is upon us. The authors here point out that change has already taken place in one form or another and, thanks to technology, the time and space constraints of the physical classroom have been overcome. Education now takes place in real time literally anywhere in the world. In our opinion, artificial intelligence can only enhance the quality of education in this direction. However, the fact that many professions require a physical presence should not be overstated. Sooner or later, thanks to artificial intelligence, this physical presence may not be necessary.

Technology itself - In this case, technology has a strong influence on the development of artificial intelligence in higher education. According to the cited authors, an infrastructure has been developed that supports the learning process through innovative learning models. In developing new models of education and supporting, the relationship between artificial intelligence and higher education can create standardised models based on generally accepted and valid learning practices. This could elevate the quality of education to a new level, transitioning from theory to practice.

\section{AiLM Model - Artificial Intelligence Learning Model in Higher Education with recommendations made}

Looking at the model below (fig. 1), it can be seen that the learning process - LP - takes place entirely in harmony with the learning model - LM, Pedagogical Model - PM and Domain Model - DM. It is well known that the model of artificial intelligence in education comprises of three main elements: Learning model LM, Pedagogical model PM and Domain model DM. These three elements have been well studied and are linked to the various artificial intelligence platforms that support them. For this reason, we will focus on them in greater detail to give a clearer picture of what is currently happening in the world of artificial intelligence and higher 


\section{Artificial Intelligence in Higher Education}

education. In order to clarify the role of the LM (learning model) process, we have developed the model below based on Fullan and Donelly's three-pronged approach (Luckin et al., 2016). Notably, we have added a significant fourth element to the learning process - the Administrative Model (AM), which binds all the elements together. We will present the role of artificial intelligence in this model and present our recommendations for the use of AI in higher education. Let's now look at each element in greater detail.

Fig. 1. Artificial Intelligence Learning Model (AiLM)

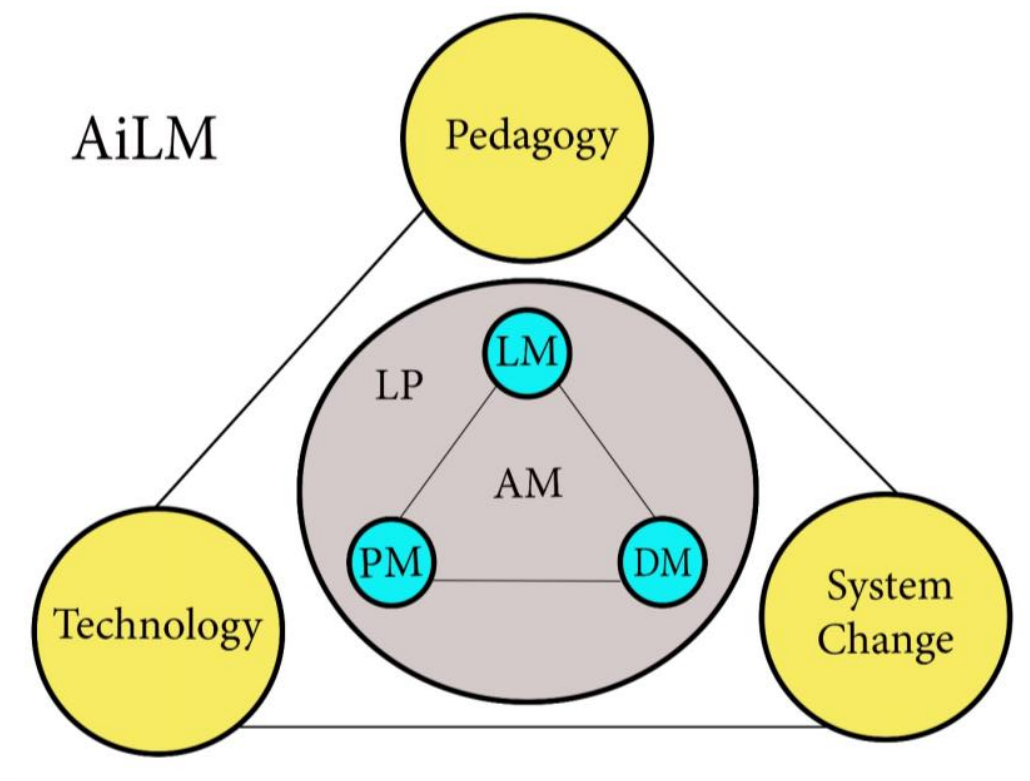

Source: Akinwalere \& Ivanov (2021)

\section{Learning Model - LM}

This embodies the learners' knowledge. Some authors argue that elements such as students' past achievements, emotional state, and involvement in the learning process should also be included (Luckin et al., 2016). In addition, it is worth mentioning that the process of learning and interaction with students will improve if students' academic qualities (developed during the learning process) can also be measured (Dampson et al., 2019). This is particularly important as the labour market has changed drastically in recent decades in terms of the types of jobs being created. This requires flexibility and many different cognitive and non-cognitive skills on the part of students. Some authors argue that artificial intelligence can be used to predict student behaviour in e-learning environments (Hussain et al., 2018). Others still argue that artificial intelligence can increase student motivation by predicting levels of motivation at an early stage (Babić, 2017).

It is possible to draw a parallel between artificial intelligence and technologies supporting online learning. In this regard, there are a number of tools at our disposal. For example, different platforms support real interaction with students (Blackboard Inc, 2022), the reporting of real-time attendance (MyAttendance'Tracker, 2016), and communication with faculty in real-time (Turnitin LLC, 2022). 
To support teachers, we recommend the provision of software to evaluate students' work (Perin \& Lauterbach, 2016). However, there are also a number of potential pitfalls of using AI in this way. On the one hand, AI eliminates the problem of subjectivity in assessment. On the other hand, there is the danger of underestimating students' capabilities due to its inability to consider additional skills and knowledge (e.g., participation during classes).

Ultimately, artificial intelligence should help to motivate students by giving them more information about the module that they will be studying. If students are better prepared in advance, they will be more confident and motivated for success. On the other hand, it is possible to limit the use of artificial intelligence in student assessment to multiple-choice tests and control tasks- the subjective role of the lecturer should not be neglected. It is also possible to make use of artificial intelligence to monitor attendance during online learning sessions to help prevent absences. Finally, artificial intelligence would be particularly useful in generating assignment topics. It is extremely annoying and monotonous for teachers to generate assignment topics without the use of technology. Instead of wasting valuable time on this, the teacher will focus on presenting the really important things in the subject. This will increase the quality of teaching and learning.

Many commentators (Hussain et al., 2018) regard some learning platforms, such as the Virtual Learning Environment and the Learning Management System, as identical e-learning products. Rather, these platforms contribute to more effective communication between students, faculty and administrators. However, in terms of our definition of artificial intelligence, we believe that these are essentially learning platforms.

It is also thought that many virtual assistants (similar to Siri at Aiphone) (Popenici \& Kerr, 2017) could be viewed as artificial intelligence for training purposes. Here, we agree that this type of software should be perceived as artificial intelligence, but only to the extent that it is capable of self-learning.

\section{Pedagogy Model - PM}

Here we look at what artificial intelligence is from a teaching point of view, embodying the knowledge and experience of teaching.

Currently, many tools are used in practice that provides feedback to students in real-time. This is a kind of platform for e-learning and communication. In order to turn this platform into artificial intelligence, a chatbot could be incorporated into existing systems. This bot could give feedback to students and explaining assignments. In addition, effective communication could be obtained with the help of artificial intelligence if part of the teaching functions are transferred to bot robots, combined with expert supervision by teachers to impart basic subject knowledge.

On the other hand, bots already teach students in some disciplines according to the sample error model. We recommend that all training institutions incorporate this process into their systems, as this type of bot is reasonably inexpensive (Tars Technologies Inc, 2022). The intelligence of these machines lies in the databases they use. These bots can measure student achievement in real-time, which is a real benefit to teachers. This provides valuable information about each student's progress and also works as a good starting point for teaching. In this part of our model, we can implement educational data mining (EDM). These are 'techniques to 'track' the behaviours of students - for example, collecting data on class attendance and 
assignment submission in order to identify (and provide support) to students at risk of abandoning their studies" ( Luckin et al., 2016).

\section{Domain Model - DM}

DM deals with the accumulation of knowledge in relation to a particular subject. Artificial intelligence is a bot that can extract and work with these data. The data represented in this case relate to the body of knowledge in a given subject. As we pointed out, this model is not designed to replace the role of the teacher. However, artificial intelligence can retrieve particular databases via 'data mining' (Witten et al., 2011), judging which ones are appropriate in the respective field of study, aiding the teacher in making decisions.

It is possible to implement a virtual learning environment that offers students and teachers the highest possible degree of reality and proximity to a practical environment. This reveals AI's vast potential for practical training. As Luckin (2016) argues, "virtual reality becomes 'intelligent' when it is augmented with artificial intelligence. AI might be used simply to enhance the virtual world, giving it the ability to interact with and respond to the user's actions in ways that feel more natural." ( Luckin et al., 2016, p. 29).

\section{Administrative Model - AM}

We have introduced this important element into the model called AM. This relates to the administrative support provided to ensure the effective operation of the learning process. It is usually carried out by the administrative department of the respective unit.

We, therefore, recommend the following:

$\checkmark$ Traditionally, this department is responsible for student recruitment. Effectively, its functions could be entirely performed by artificial intelligence and bot machines that conduct interviews to assess the suitability of candidates.

$\checkmark$ Student attendance could be checked by artificial intelligence, eliminating the human factor entirely and preventing the manipulation of attendance registers.

$\checkmark$ Creating a database related to a student file is plausible with artificial intelligence. Here, we believe artificial intelligence will be able to reduce many human hours of work related to administrative tasks.

$\checkmark$ The preparation of official documents related to the status of students could be performed using AI. Here, artificial intelligence could prepare documents required by external institutions to certify a student's status.

Of course, the potential application of artificial intelligence is vast; however, there are currently few opportunities to put it into practice. In contrast, our model tries to show where artificial intelligence could be implemented in the learning process and how this could be achieved. Although machines could replace administrative jobs, certain roles, such as those involving teachers, cannot be replaced entirely by artificial intelligence; modern technology must support and enhance the teaching process, not replace it. In our opinion, the charismatic role of the teacher-pedagogue will be even more relevant in the future. We would therefore advocate new modern styles of teaching and the restoration of the lecture process. In practice, this suggests that lecturers must accept the role of educators and, by personal example and remoteness of science and teaching, demonstrate to the new generation that technology, under the guise of artificial intelligence, is capable of complementing the genius of the human 
brain. Ultimately, our position stands firmly behind quality education supported, not fully realised, by artificial intelligence.

\section{Conclusions}

In education, AI remains a sleeping giant. 'Breakthrough' AI applications for teaching and learning are unlikely to emerge from within mainstream higher education. A look at the AI model above highlights the key question whether technology should aim to replace teachers and instructors through automation or whether technology should be used to empower not only teachers but also learners. If AI does become immensely successful in reducing the costs of teaching and learning, what will the cost be to us as humans?

Some countries are taking advantage of the abundance of educational data that came with the advent of the Information Age. These countries and their respective educational institutions have begun harvesting insights from large masses of data to provide more personalised learning experiences. Of course, the elephant in the room begs noticing, i.e. the challenges around data accuracy and the implementation of AI. Education systems have also been actively reforming themselves to ensure that learners are acquiring the skills required by an AI-enabled future workplace. This lifelong learning orientation is, of course, appropriate in light of how fast AI technologies are evolving. As such, this process of rethinking and redeveloping educational programmes in response to AI might need to become a regular and continuous process.

Inevitably, AI is a field that spurs innovation and, by doing so, increases countries' competitiveness. Countries will continue competing in such a rich and rapidly evolving arena. Yet, at least when it comes to education, there is also room for cooperation, the basis of which is knowledge sharing. There is a need for more information about how countries are moving forward in this uncertain and constantly changing territory to promote the discussion and the relevance of adopting comprehensive perspectives of AI in education.

\section{References}

Alexander, B., Ashford-Rowe, K., Barajas-Murphy, N., Dobbin, G., Knott, J., McCormack, M., Pomerantz, J., Seilhamer, R., \& Weber, N. (2019). EDUCAUSE Horizon Report: 2019 Higher Education Edition. EDUCAUSE.

Andrews, S., Bare, L., Bentley, P., Goedegebuure, L., Pugsley, C., \& Rance, B. (2016). Contingent academic employment in Australian universities. LH Martin Institute. https://melbourne-cshe.unimelb. edu.au/_data/assets/pdf_file/0009/2564262/2016-contingent-academic-employment-in-australianuniversities-updatedapr16.pdf

Babić, I. (2017). Machine learning methods in predicting the student academic motivation. Croatian Operational Research Review, 8(2), 443-461. https://doi.org/10.17535/crorr.2017.0028

Bates, T. (2018, December 3). Another perspective on AI in higher education | Tony Bates. Www.tonybates.ca. https://www.tonybates.ca/2018/12/02/another-perspective-on-ai-in-higher-education/

Bayne, S. (2015). Teacherbot: Interventions in automated teaching. Teaching in Higher Education, 20(4), 455467. https://doi.org/10.1080/13562517.2015.1020783

Becke, S., Brown, M., Dahlstrom, E., Davis, A., DePaul, K., Diaz, V., \& Pomerantz, J. (2018). Horizon Report 2018 Higher Education Edition Brought to you by EDUCAUSE. EDUCAUSE. https://library.educause.edu/ /media/files/library/2018/8/2018horizonreport.pdf

Blackboard Inc. (2022, January 20). Distance Learning Platform with Web Conferencing \& Collaboration, Blackboard. Www.blackboard.com. https://www.blackboard.com/en-uk/teaching-learning/collaboration-web-

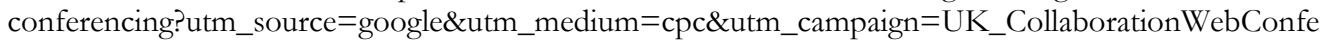




\section{Artificial Intelligence in Higher Education}

rencingBrand\&utm_term=blackboard $\% 20$ video $\% 20$ conferencing\&gclid=Cj0KCQjw_8mHBhClARIs ABfFgpio2JeAWN5DZhdmi

Bostrom, N. (2017). Superintelligence: Paths, dangers, strategies. Oxford University Press, Cop.

Contact North. (2018, September 28). Welcome to teachonline.ca | contact north | teachonline.ca. Teachonline.ca. https://teachonline.ca/

Dampson, D., Owusu-Mensah, F., Apau, S., \& Osei-Owusu, B. (2019). Learner Support Gaps in Distance Learning: The Case of Institute for Distance Education and e-Learning, University of Education, Winneba. Advances in Social Sciences Research Journal, 6(8), 487-499. https://doi.org/ 10.14738/ assri.68.6990

Deakin University (2014, October 11). Deakin IBM Watson. Archive.li. http://archive.li/kEnXm

Diamandis, P. H., \& Kotler, S. (2020). The future is faster than you think: How converging technologies are transforming business, industries, and our lives. Simon \& Schuster.

Ford, M. (2018). Architects of intelligence: the truth about AI from the people building it. Packt Publishing Ltd.

Fullan, M., \& Donnelly, K. (2013). Alive in the SwAmp Assessing DigitAl innovAtions in eDucAtion. Nesta.

Hussain, M., Zhu, W., Zhang, W., \& Abidi, S. M. R. (2018). Student Engagement Predictions in an e-Learning System and Their Impact on Student Course Assessment Scores. Computational Intelligence and Neuroscience, 2018, 1-21. https://doi.org/10.1155/2018/6347186

Janalta Interactive. (2021). What is a Botnet? - Definition from Techopedia. Techopedia.com. https://www. techopedia.com/definition/384/botnet

Jonassen, D., Davidson, M., Collins, M., Campbell, J., \& Haag, B. B. (1995). Constructivism and computermediated communication in distance education. American Journal of Distance Education, 9(2), 7-26. https://doi.org/10.1080/08923649509526885

Kaku, M. (2012). Physics of the future: the inventions that will transform our lives. Penguin.

Kelly, K. (2017). The inevitable: understanding the 12 technological forces that will shape our future. Penguin Books.

Kübler, A., Holz, E. M., Sellers, E. W., \& Vaughan, T. M. (2015). Toward independent home use of braincomputer interfaces: A Decision Algorithm for Selection of Potential End-Users. Archives of Physical Medicine and Rehabilitation, 96(3), S27-S32. https://doi.org/10.1016/j.apmr.2014.03.036

Luckin, R., Holmes, W., Griffiths, M., \& Pearson, L. (2016). Intelligence Unleashed An argument for AI in Education. https://static.googleusercontent.com/media/edu.google.com/bg//pdfs/IntelligenceUnleashed-Publication.pdf

MyAttendanceTracker. (2016). Attendance Tracking Software Online. Myattendancetracker.com. https://www. myattendancetracker.com/

Pearson. (2021). Artificial inteelingen in Higher Education. Pearson. https://www.pearson.com/uk/ educators/higher-education-educators/higher-education-catalogue/ema-course-structure/computerscience/artificial-intelligence/artificial-intelligence--ai-.html

Perera, M., \& Aboal, D. (2020). The Impact of a Mathematics Computer-Assisted Learning Platform on Students' Mathematics Test Scores. Digital.fundacionceibal.edu.uy. https://digital.fundacionceibal.edu.uy/ jspui/handle/123456789/225

Perin, D., \& Lauterbach, M. (2016). Assessing Text-Based Writing of Low-Skilled College Students. International Journal of Artificial Intelligence in Education, 28(1), 56-78. https://doi.org/10.1007/s40593-0160122-z

Popenici, S. A. D., \& Kerr, S. (2017). Exploring the impact of artificial intelligence on teaching and learning in higher education. Research and Practice in Technology Enhanced Learning, 12(1). https://doi.org/ 10.1186/s41039-017-0062-8

Postman, N. (1983). The disappearance of childhood. Vintage.

Russell, S., \& Norvig, P. (2010). Artificial intelligence: a modern approach (3rd ed.). Pearson.

Salmon, G. (2000). E-moderating: the key to online teaching and learning. Routledge.

Sharma, Y. (2011, October 12). Boost to university-industry AI research collaboration. University World News. https://www.universityworldnews.com/post.php?story=20181012084845359

Tars Technologies Inc. (2022, January 20). Course Application Chatbot Template, Education Course Enrollment Chatbot, Chatbot for Educational Institutes, Conversational Landing Pages by Tars. TARS. https:/ /hellotars.com/ chatbot-templates/education/SJeCG7/course-enrollment-chatbot

Border Crossing 
Tegmark, M. (2018). Life 3.0 : being buman in the age of artificial intelligence. Penguin Books.

Turnitin LLC. (2022). TurnitinUK. Www.turnitinuk.com. https://www.turnitinuk.com/login_page.asp

UNESCO. (2019). Artificial Intelligence in Education: Challenges and Opportunities for Sustainable Development (pp. 1-48). United Nations Educational, Scientific and Cultural Organization.

UNSW School of Computer Science and Engineering. (2021). Artificial intelligence, Computer Science and Engineering - UNSW Sydney. UNSW Sites. https://www.unsw.edu.au/engineering/our-schools/ computer-science-and-engineering/our-research/research-groups/artificial-intelligence

Viktor Mayer-Schönberger, \& Cukier, K. (2014). Big data: a revolution that will transform how we live, work, and think. John Murray.

Williamson, B. (2014). Governing software: networks, databases and algorithmic power in the digital governance of public education. Learning, Media and Technology, 40(1), 83-105. https://doi.org/ 10.1080/17439884.2014.924527

Witten, I. H., Frank, E., \& Hall, M. A. (2011). Data mining: Practical Machine Learning Tools and Techniques. Elsevier.

Zuboff, S. (2019). The Age of Surveillance Capitalism: The Fight for a Human Future at the New Frontier of Power. Public Affairs. 